\title{
Smart City and Green Development
}

\author{
Polzonetti A. ${ }^{1}$ - Sagratella M. ${ }^{2}$ \\ ${ }^{1}$ University of Camerino (ITALY) alberto.polzonetti@unicam.it \\ ${ }^{2}$ E-LIOS srl Spin Off Unicam matteo.sagratella@e-lios.eu
}

\begin{abstract}
Smart city is a strategy that aims at employing technology to improve life quality in urban areas. Among its main objectives, the environment quality is the top one. The $E U$ vision on smart cities is strongly focused on energy efficiency, on nearly-zero energy buildings, on the reduction of CO2 emissions and so on. Therefore, some aspects of the smart city overlap with the idea of green city. Green city is an older but always updated vision, that aims at creating cities with a lower environmental impact, able to reduce the consumption of natural resources and to improve the quality of air and water.

This study is designed to understand if smart city and green city have similarities, to what extent they do overlap and how many synergies it is possible to create pursuing these two urban strategies at the same time. After a deep analysis of the international literature about these two subjects, we examined the portfolio of the initiatives that are usually employed, and we compared it with the international indicators related to the green city performances. We outlined overlapping areas and reached conclusions on the convergence of smart and green urban policies.
\end{abstract}

\section{Introduction}

Currently, the topics of green economy and sustainable growth are highly relevant, since the customers/consumers/citizens' sensitivity towards the environmental quality has increased. Economy and respect for the environment cannot and shouldn't be considered as opposing topics but rather as 'two sides of the same coin', as objectives to be both pursued in synergy and harmony [8].

This theme is more keenly felt by cities: in fact, the continuous and strong dimensional growth of urban centres produces an exponential increase of the pollution and the consumption of energy and natural resources such as water.

Besides, cities are the place where people, students and enterprises are concentrated: cities have always been the place selected for the production of goods and services, for related marketing and consumption. They are also the place where the tourist flows are more and more directed: their demand increases the consumption of resources and can make unsustainable the unresolved concerns related to, for example, mobility and pollution [15].

Cities are meeting the new needs and requirements by means of strategies that can be defined digital, green, smart and sustainable. These four strategy fields do not coincide with each other but show strong overlapping areas.

- The digital city is a city that largely employs ICT to convey data and information and to create bidirectional communication channels between citizens, institutions and enterprises.

- The green city is a city that aims at developing infrastructures, spaces, facilities and urban activities with a low or even with no environmental impact.

- The sustainable city is a city that aims at developing a socio-economical urban context able to balance economic development with respect for the environment and social equity.

- The smart city is a city focusing on the use of technologies to improve life quality in urban areas.

Overlaps and differences can be easily seen among these strategic policies for the city development. A local public transport system using advanced technology and ICT to reduce $\mathrm{CO} 2$ emissions and to provide a better service to all citizens, with a special attention to the most disadvantaged groups of people such as disabled, older people, mums with strollers, is at the same time digital, smart, green and sustainable. On the contrary, the increasing of urban parks is a green project only, the General Register Office digitisation is a digital project only, the efficiency raising in energy production in smart grid is (almost) exclusively smart, and so on.

The concept of smart city that has spread in recent years tends to take in high consideration the smart, green and digital aspects simultaneously [10]. This city development line is emerging thanks mainly to the European Union guidelines that combine the guidance with funds and financing for the research and the implementation of smart projects, and it ends up prevail vs. other interpretations of smart city $[13,1]$. 
Actually, the concept of smart city, both in academic definitions and practical implementations, takes on much wider and more heterogeneous meanings and contents and, drawing its perimeter seems quite difficult. Nevertheless, in the smart programs of the cities, the concern for the environment constantly appears as a core element.

Therefore, the research question is the following: which is the relation between green city and smart city? Are there common dimensions (and then indicators related to each dimension)? Is it possible to design policies that concur to the achievement of such common objectives?

\section{Smart, digital, green e sustainable}

\subsection{The origin of the concept of smart city}

The branch of research and government named smart city is today among the main strategies not only of cities but also of global member states and organizations such as UN, OECD, European Union. Cities have started many smart initiatives, and just as many are the European programs financing such initiatives and the reports, studies and researches of national and supranational bodies on this subject. However, the definition of smart city is not yet univocal or consolidated [14].

The main reason of this indeterminacy lays in the process that led to the success of the so-called smart initiatives. Often a bottom-up driven process, namely driven by isolated initiatives of citizens and enterprises; a process that started in territories, in the urban areas of some pilot cities and then has spread worldwide [5]. 2011). To understand what a smart city is, it is first of all necessary to carry out three types of analysis:

- The historical analysis, studying how the topic has started and developed and in which time frame;

- $\quad$ The territorial analysis, exploring the coming up of smart experiences, researches or policies in urban areas and in the regions of the world, examining also how the phenomenon started and progressively spread itself;

- The terminology and content analysis that compares the different terms used to identify the cities that started a path for the improvement of the living conditions in their territories, thanks to the more or less intense use of advanced technologies such as - but not only - the ICT and the minimisation of environmental impact of the cities.
The historical analysis highlights how the smart city has far-off roots and how it constantly intertwines with the concept of digital city [9].

The historical analysis is a first distinctive element between digital city and smart city, that underlines the different development that the two experiences had in the past twenty years. Other relevant differences emerge from the analysis of territorial and content elements of these two smart city metaphors. The review of existing literature allows us to draw the most quoted definitions of digital city and smart city. By reading and interpreting them, some aspects become immediately clear, some of them can be deducted from the digital or smart name of the city.

The digital city is strictly related to the use of information technology and especially to some of its implementations such as Internet, broadband and fast Internet connections at urban areas level, the use of mobile access devices, not only the traditional PC, but especially, the so called smart devices (and here it is the first source of terminology confusion) such as smart-phones and tablets.

Among related key topics we find broadband and connectivity, that make the digital city also a wired city or a network city [7], the use of open data structures, thanks to which public information is accessible and available to everyone and this make the digital city also an information city [3]; the creation of digital services offered to citizens both by public bodies and by private enterprises and organizations [6]; the virtualization of spaces, behaviours and relationships that lead to the creation of a sort of virtual city overlapping the real one, with its own rules, behaviours, relationships etc. This makes a digital city also a virtual city or an ubiquitous city $[19 ; 2]$.

The definitions of digital city do not talk of quality of life explicitly, but they show that the process of transformation of the city generated by digitisation policies is fully oriented towards the citizen and his needs. And indeed, one of the main obstacles to the full realization of the digital city is mainly the digital divide, which separates those who have the skills to access digital information and services from those who haven't, creating a form of virtual exclusion [16]. Exclusion not only in terms of fruition, but also in terms of offer, with some enterprises and public bodies that are able to offer digital information and services and others that do not have the knowledge and the skills to do so and remain excluded from the implementation of the digital city and from related appropriation of returns.

The analysis of the main definitions of smart city, highlights the primary characteristics of what a smart city should be. A first reading of the definitions suggests, in the first place, that the concept of smart 
city is much more indefinite than the digital city one. As a matter of fact, some definitions are impalpable and identify the smart city just as a city able to create good living conditions for its citizens, regardless of how it manages to do that and of what tools or technology are used [11]. Some definitions recall the digital city, recognising in those previous and more mature experiences a basis or a part of the smart city [5]. Other definitions are more concrete and refer to smart initiatives, infrastructures and activities mainly connected to some key elements of living in the city such as public transport, energy production and consumption, pollution and environmental impact of buildings and human or productive activities[10].

Actually, the main academic definitions of smart city are not able to represent what the smart city really is in the mind of those who - in municipal Governments, enterprises and University Departments - are involved in its design and realization. A more practical vision can be extrapolated from the reports of the major technological players, IBM, Oracle or Microsoft for example, or of the big research centres such as Gartner and the Stanford University, or even more from visiting the websites of the several Italian, European or global cities that have taken the path of smartness. The analysis carried out enabled us to understand that there are some common themes that can be found both in academic studies and in the empirical implementations of the smart city.

The main topic, shared by all the sources we analysed, regards the negative environmental impact of cities and the need of containing or reducing it, especially through the reduction of $\mathrm{CO} 2$ but also through waste treatment, water quality etc. As a function of the relationship between city and environment, the smart city focuses on the enormous amount of energy used by the city, due to its residential and productive settlements and to the premises of enterprises, places of study and work, public bodies and, therefore, the need, on the one hand, of reducing the energy requirements and, on the other hand, of producing energy from clean and renewable sources.

A smart city is not such if it does not make a wide use of the most innovative technology. Central is the key role of technology in the pursuit of all the smart city objectives and of the technology-based orientation of smart strategies, as well as the technologic, economic and social innovation that envisages in the smart city also a place of economic development with high added value and with a high content of technology and knowledge [21].

A theme partly included in the smart city concerns the so-called smart community; in fact, it is an evolution of the digital city that aims at connecting citizens, at making available open access to online information and at the fruition of digital services also with mobile devices. The topic of smart community draws the attention on the role of citizens and on their active involvement in city smartness projects.

Finally, even the macro-objectives of the smart city (at a general level) are homogeneous: the smart city aims at the citizens' well-being; a tangible well-being, based on ease of access to services and infrastructures, on economical well-being, on participation and social inclusion. A well-being built on the contrast to the typical inconveniences deriving from living in a city, such as traffic, pollution, congestion of public or private transport, and on the study of innovative solutions to limit such inconveniences. According to this last and wider meaning, the smart city becomes a city able to carry out a positive role for its residents and visitors, regardless of the devices used to achieve the smartness objectives.

\subsection{From smart to green}

The study and analysis of the materials collected and described in the previous paragraph allows us to highlight two concepts of smart city. The first one could be defined as wide: according to it the smart city is an intelligent city creating excellent living conditions for all its citizens. The purpose of this concept is to emphasize how nowadays the quality of life strongly passes through cities, urban areas, through the activities taking place there and the ability of local policies to achieve good living conditions, that are often hindered by the eccessive dimensions of cities and by their complexity.

The second concept, the more interesting one for our study, just defines the smart city as a subset of the successful city, that includes some issues such as infrastructures, energy, environmental impact, use of ICT; and where technology and innovation have a key role; all this is aimed at improving the quality of life in urban spaces and to attracting smart, innovative and fully developed persons and enterprises there.

According to this better focused meaning, the smart city actually takes on its own features, where technology, respect for the environment, use of ICT, applied to the physical elements of life in the city such as buildings and public transport, but also the virtual elements of urban life such as the need of receiving digital services or to accessing online information, are key elements to define a development path that is both sustainable and inclusive. According to this meaning, the smart city becomes partly green city, namely green city respectful of the environment, partly sustainable city, a city that defines paths of socio-economical development able to guarantee economic well-being, social inclusion and environmental quality to those living within its boundaries, not necessarily 
administrative ones but within the city area of influence.

Beyond definitions, the main difference between green city and sustainable city is not only the time frame: in the green city it is based on the present, in the sustaible city it is inter-temporal and through present and future generations. The main difference is that the sustainable city aims to reconcile environment, economy and social inclusion, stating that the respect for the environment and the sustainable use of natural resources are not in contrast with the economic wellbeing and the creation of value by enterprises and that the sustainable development has to aim at creating a balanced wealth also with regard to its distribution, avoiding the concentration of wealth in the hands of a few to the detriment of the economic and social inclusion of many. A sustainable city is also a fair city that aims at guaranteeing the internal well-being for everyone, no one excluded.

From the comparison between sustainable and smart city, we notice some overlapping elements between the two concepts. The main ones are the environment impact and the use of natural resources: they are present both in the sustainable city and in the smart city. Both these two ideas of city consider the economic development as a key element of urban life that, for the sustainable city, should be reconciled with the natural environment, whilst in the smart city; the smartness is even a source of sustainable economic growth. Citizens play a central role but is intended in two different ways: in the sustainable city it primarily pursues the aims of equity among people and generations in the distribution of economic and natural resources, whilst the smart city directs its efforts towards the quality of life in urban areas. The social inclusion is a topic that has been added only in recent times and, however, in a marginal and indefinite way.

What certainly distinguishes the smart city from the sustainable one is the key role played by technology and, in particular, by ICT and by the most innovative ad advanced technologies in the realization of smart, quality and attractive cities, where people can live well, and where it is possible to achieve a widespread well-being and to combat social exclusion.

When they started to talk about sustainable economy and cities, the information technologies were still in a pre-Internet phase and confined in large enterprises and organisations; the pervasiveness of ICT in daily life of SME and citizens was still far away. Also the dimensions of cities were more contained, megalopolis could be countend on the fingers of one hand and the psychological threshold of the $50 \%$ of the world population that goes to live in cities was not overcome yet. These elements modified the metaphore of city, but they did not reduce the awareness of how urgent it is to answer to the needs of life in urban areas, to environmental decay, to the use of energy sources, mainly in cities, that from the Middle Ages to the present days, have been, and increasingly will be, the focus of economic and social life.

\section{Green and smart city: a comparison of dimensions and indicators}

\subsection{Dimensions and indicators of the green city}

Within the framework of general policies aimed at pursuing a green vision for urban agglomerations, first we can refer to OECD contributions. In particular, the topic of the green growth of the Oecd Declaration on Green Growth, of June 2009, was subsequently taken up and contextualised in the Green Cities Programme. This program aims at evaluating how much the urban green growth and the policies for sustainability can contribute to improving both the economic context and the environmental quality of metropolitan areas and, consequently, to increase the contribution of such areas to the national growth, to life quality and to competitiveness. In particular, the Green Growth Strategy identifies and promotes the activities necessary to reduce the environmental impact as potential sources of growth and refers to the need of internalise the negative environmental externalities. In these contributions, the green growth is intended to harmonise economic growth and environmental sustainability. As such, it only partially coincide with the concept of sustainable development since it focuses on economic efficiency and environmental protection that are only two of the three pillars of the sustaible development (that, as is known, includes also social equity and justice). The effort and the wish is that the social interests be integrated in the commitment for green growth [12].

Urban green growth especially focuses on economic growth and on development through urban activities able to limit the negative environmental externalities and the impact of natural resources and environmental services [17]. In fact, it is evident that the urban agglomeration significantly affects, mainly in new fast-growing metropolises (i.e. in the Far East), traffic congestion, pollution and the impact on the ecosystem and, hence, on the natural resources.

The dimensions of the green city can be expressed in a series of indicators, many of which have given rise to the need of synthesize the different suggested variables in a single code.

Concluding this first part focused on dimensions and indicators of the green city, we can state the following: 
- The suggested dimensions cover the traditional areas of environmental protection: water, air, earth (more in general, non-renewable resources), waste management and energy, as well as human activities strongly affecting these resources: urban mobility, waste and buildings management. However it is evident that, for example, urban mobility is strictly connected to the quality of air and can generate separate assessments of the interconnected and interdependent indicators;

- The suggested indicators are sometimes already operationalized, i.e. expressed as variables. The schemes propose then mixed (and therefore inconsistent) sets of indicators and variables;

- No indexes are built with the suggested variables: the task of synthetizing the multiplicity of variables and identifying a form of synthetic evaluation is left to the researcher who adopts the scheme.

It follows that the above is an interesting contribution to a more accurate and articulated knowledge of the green dimensions of a city, but it is not yet a valid tool for the measurement of the urban realities performance: the conceptual framework seems in fact to leave aside the definition of the strategic objectives of each specific city to which evaluations and measurements should necessarily and strictly be connected.

According to this framework and to the purposes of this study, it is evident the need of having at least one set of dimensions to be able to evaluate how smart initiatives can be qualified also as initiatives pursuing the green objectives of a city. Based on our findings, we suggest the following dimensions of a green city:

- $\quad$ Air quality

- Land use and consumption

- Energy consumption (efficiency raising, alternative and renewable energies)

- Waste production and management

- Mobility, transport and logistics

\subsection{Dimensions and indicators of the smart city}

As we have seen, the relevant definitions are not univocal. In the first place because the city smartness is a process and, as such, continuously changing and evolving. Besides, the main object on which the process takes place, i.e. the city, shows some typical characters as well as a multiplicity of different connotations (dimension, localisation, resources, socioeconomic and political context, etc.) that make difficult and especially, in our opinion, not very useful, any attempt of referring to "a unit". It is certainly more functional to our purposes to identify which are the city dimensions that come into play in the context of a smart approach. We therefore intend to focus on two scientific contributions identifying those that should be the main characteristics of smart cities, the significant dimensions of their development that, consequently, identify the indicators pertinent to each dimension.

With this regard, we refer to Giffinger et al. (2007) who stated that the smart city is "a city well performing in a forward-looking way in economy, people, governance, mobility, environment, and living, built on the smart combination of activities of self-decisive, independent and aware citizens". This approach not only considers the technology and digitalisation of structures and services (digital city) essential, but contemplates them in a project of improvement of life quality and in a wise management of resources, mainly natural ones (green city), through a participative governance (smart city). For this vision of city, the study identifies six areas of intervention whose design and management should be carried out in an intelligent perspective, built according to available resources and knowledge and with the active participation of independent and aware citizens. Every city can be defined as smart to the extent it is commited in the realization of:

- $\quad$ smart economy: competitiveness

- $\quad$ smart environment: natural resources

- smart governance: participation

- $\quad$ smart living: quality of life

- $\quad$ smart mobility: transport and ICT

- $\quad$ smart people: social and human capital.

Such dimensions are declined in 31 factors that make up the framework for the identification of indicators and the consequent evaluation of the performances of a smart city. In particular, this means to assess and measure aspects such as: entrepreneurial spirit, economic image, productivity, flexibility of labour market (that fall within the smart economy), environmental protection, pollution, sustainable management of resources (smart environment), partipation in decision-making processes, public and social services, transparent governance (smart governance), individual safety, cultural and educational structures, touristic attractiveness, social cohesion (smart living), accessibility, availability of ICT infrastructures, sustainable, innovative and safe transport systems (smart mobility), continuous professional training, flexibility and creativity, mind and cultural openness (smart people).

The results provided by the adoption of such framework are undoubtedly interesting since they allow to highlight the best city performances, also with respect to specific issues.

It is interesting to remember the ranking of the Smart City lndex carried out by the consulting company Between on 116 Italian chief municipalities 
on the basis of thematic areas. This index is not aimed at measuring the absolute level of smart innovation but the distance between the best city $($ score $=100)$ and the others [4]. The analyzed dimensions are the following:

$$
\begin{array}{ll}
\text { - } & \text { broad band } \\
\text { - } & \text { smart mobility } \\
\text { - } & \text { smart health } \\
\text { - } & \text { smart government } \\
\text { - } & \text { alternative mobility } \\
\text { - } & \text { renewable energies } \\
\text { - } & \text { energy efficiency }
\end{array}
$$

On this basis, were identified 19 sub-areas and 153 indicators representing a particularly innovative contribution for the identified areas and for the adopted measurements. Besides, it is interesting to notice that the adopted meaning of smart city first of all requires that it may be possible to observe a substantial difference between a "before" and a "after", that such changes derive from a path pursued and contextualizable in a clear vision but, above all, that such changes have a strong connotation of innovation, "tangible" and "widespread" within the city.

The contributions of Giffinger et al. (2007) and Between (2013) however point out the typical limits of rankings: they are a "photograph" of the situation of a group of cities providing a synthetic vision of a complex phenomenon but they do not satisfy the need of an articulated and specific knowledge. In fact, many characteristics of the smart city are analysed in dychotomous key only or otherwise different weights are assumed (discretional) or, again, are adopted wide or limited visions of a same dimension characterizing a smart city. The reason of these limits is clearly, because the definition of smart city is not univocal and the measurement of the performances of the cities that have started integrated projects are still scarce. The dimensions and indicators suggested by such contributions can however be a valid support for the evaluation of the policies to be included in order to identify if and to what extent they are consistent with the dimensions a smart city should have.

A significantly different approach is offered by the Siemens' Efficient Cities study carried out by Cittalia that aims at analyzing a macro group of 54 mediumlarge cities based on their infrastructural allocations [20]. The examined areas were urban environment quality, real estate assets, sustainable mobility and logistics, renewable energy, healthcare. The final result is the identification of six homogeneous groups of similar cities in which the different areas combine themselves bringing out one or more components: the cities of the environment, of the well-being, ideal cities, cities of the good living and of mobility, cities under development, of the energy.

Our interest for this study is based on its attempt to provide a richer and deeper, and then complete, knowledge of the city, through a multi-level classification: an initial level, based on factor analysis in main components (PCA) and a final one based on cluster analysis.

On the basis of a careful analysys of the doctrin' different contributions about the dimensions that should characterise green and smart cities, it emerges that the environment and energy topics are always present, though with different extent and importance, within the smart city concept and dimensions. As concerns the concept of green city examined in the first part, the illustrated contributions highlight in fact how the smartness of a city may not disregard a vision that considers essential the safeguard of natural resources, above all the non-renewable ones, the reduction of the environment impacts caused by human activities and enterprises processes, energy efficiency, and safety. This vision seems to include, or at least to overlap significantly, the green city concept with the smart city one.

\section{Italian Smart City}

Some Italian cities are an interesting, often mentioned, case of city planning and transformation according to a smart vision that began in 2010. The underlying vision, shared with stakeholders, is based on the way the term smart city is intended: "The Smart City improves the living quality through a sustainable economic development, based on research, innovation, technology and driven by the local leadership in a process of integrated planning ".

The annual report examined was carried out by FPA in order to photograph the situation of Italian cities on their path to become "smart", that is to say nearer to citizens' need, more inclusive, more livable. FPA identified and analysed 15 urban dimensions that, in the national and international context, set out the objectives for the cities (poverty, education, air and water, energy, economic development, occupation, tourism and culture, research and innovation, digital transformation and transparency, sustainable mobility, waste, public green, soil and territory, legality and security, governance). (ICITY RATE 2017)

The set of these initiatives shows the participation of a large number of players: public subjects, private companies and citizens. The analysis, based on the description of the action and of the estimated result, provided a classification of the initiatives according to 5 dimensions among the ones suggested above: air 
quality, land use and consumption, energy consumption (efficiency raising, alternative and renewable energies), waste production and management, mobility, transport and logistics. As shown in Table 69 initiatives currently developed as smart (equal to the $68 \%$ of the total) show aspects that define them as green initiatives. Compared to the dimensions identified, the actions connected to the energy topic (containment of energy consumption, reconversion to alternative or renewable energies, etc.) show a higher frequency. Several are the initiatives connected to mobility, transport and logistics, too: many of which are classified also in the topic area "air quality and reduction in $\mathrm{CO} 2$ emissions".

\begin{tabular}{|l|l|}
\hline & $\begin{array}{l}\text { Number of } \\
\text { smart actions }\end{array}$ \\
\hline Air quality & 7 \\
\hline Soil use and consumption & 6 \\
\hline Energy consumption & 18 \\
\hline Waste production and management & 2 \\
\hline Mobility, transport and logistics & 14 \\
\hline GREEN IMPACT & 47 \\
\hline
\end{tabular}

In the examined case, it is clear that the characteristics and factors of the smart city show areas of evident overlapping with those of the green city as well as areas that are only partially common.

\section{Conclusions}

The smart city topic is gaining a position of great interest and newness for public administrations but also for the research community and for enterprises. The literature analysis highlights how the smart city concept does not have an accredited and fully shared definition yet. This is mainly due to a process of bottom-up type implementation of the smart city: local administrations, enterprises and associations moved independently to carry out smart small actions or large projects, often without a direction or planning able to define vision, strategies, goals and contents of the smart city. The definitions are based on the collection of experiences under a unifying hat, trying to keep together a multiplicity of aspects sometimes very different one from the other.

On the contrary, the green city has older origins and a better-defined perimeter. Provided that the city is a huge agglomerate - larger and larger from the geographical and population points of view - that consumes natural resources and produces pollution, the green city is a urban planning strategy that tries to make the city greener thanks to public actions and single citizens behaviours aimed at the respect of the environment, that, at the same time, allows to its residents and visitors to enjoy healthier urban spaces.
The purpose of the Research questions of the study was to understand if there are relationships between smart city and green city, which are these relationships and how these two urban strategies can be directed towards this goal taking advantage of positive synergies. The analysis of the scientific literature, of national, international and local experiences on the smart city topic highlights that, among the several themes falling in the smart city perimeter, the environmental policies have a key role. This generates a partial overlapping between smart city and green city this does not mean that the two urban strategies fully coincide, nor that the green city can be considered as a subset of the smart city, because several are the differences that we can find in literature and in the analysis of empirical cases.

The key element that characterizes the smart city is technology, be it Information Technology or other engineering technologies applied to typical infrastructures of the urban fabric, such as roads, buildings, public lighting, transport, etc. On the contrary, the green city key element is the environment and its protection in every possible meaning of the word. The protection of the environment is also the clear objective of the green city, whilst the smart city has a much wider, ambitious but vague objective, that is to say, to improve the quality of life in the urban context. By intertwining above key elements and objectives, we can identify the overlappings between smart city and digital city. If we want to define such overlapping, we could say that smart city and digital city coincide where technology is employed to reduce the city impact on the use of natural resources, on energy consumption and soil, on air and water pollution.

In the above overlapping, it is possible to identify common dimensions, shared indicators and synergic policies to go towards a city that is both smart and green. In fact, the common dimensions are exactly those on which technology can intervene on taking positive actions on these green topics: air quality, soil use and consumption, energy consumption, waste management, logistic mobility and urban transport. The common indicators are those that aim at measuring the green impact obtained by smart actions, namely activities for the environment protection that employ innovative technologies. Let us think about the use of ICT to offer remote services and to avoid unnecessary travels the use of technologies for the production of energy from clean and renewable energy sources, the increase of energy efficiency of buildings, and so on.

We should keep in mind that not all the smart actions are also green and the other way round: it is therefore up to each city to determine what are its smart objectives, its green objectives and to identify 
overlappings and synergies to be supported with appropriate political, administrative and design measures. The specificity of the choices of every single city, though included in a smart/green overall vision common to other cities, clearly stands out from the empirical analysis of the report.

In the report, it is evident that the smart actions and projects were born in the absence of a well-outlined strategic framework and of definite objectives: this does not allow either to apply prioritization criteria among the actions to be carried out, or to measure and evaluate the achieved results. It follows that in the smart perimeter is included a really too wide and heterogeneous range of actions very different one from the other and lacking shared objectives.

Besides, the detailed analysis of all smart actions and projects of the report highlights how, mainly as regards European projects, the overlapping of smart and green strategies is very high. We should consider the following: the European projects are guided by strategic guidelines of the European Union, that tends to attribute to the smart city concept a much greener content than that emerging from the literature.

Overall, regarding the smart projects highlighted in the report, it also emerges that the energy component is predominant. Here we have to make another consideration: smart cities, thanks to the technological component, are a topic that strongly involves also the hi-tech sector companies that are particularly interested in the smart city as a potential market for their technological products. From the analysis of Genoa case, it comes into light that, lacking the city its own strategic vision, the choices of priority areas were heavily influenced by two forces: the areas where the European Union placed funds and the interest of partner companies of the Smart Cities.

In conclusion, both the literature analysis and the study of an empiric case allowed highlighting that a large shared area (Research question 1) exists between smart city and green city, whose dimension is influenced by the choices and priorities of each city with respect to the green objectives that can be achieved by using smart technologies. The dimensions of this overlapping regard the use of natural resources, energy consumption and polluting emissions (Research question 2). The smartness and greenness indicators of the city have to be applied considering that not all the smart activities have green impacts, and not all green actions are also smart, so that an indicator such as the reduction of $\mathrm{CO} 2$ emissions should be interpreted in relation with the actions that generated it (Research question 3). Lastly, as regards the policies common to the smart city and green city strategies (Research question 4), relevant synergies are depending on the choices and on the vision of each city. It is up to each city to choose if and to what extent to be smart or green and if to pursue the green objectives through technology, citizens' virtuous behaviour or both.

\section{References}

1. Ahvenniemi, H., Huovila, A., Pinto-Seppä, I., \& Airaksinen, M. (2017). What are the differences between sustainable and smart cities?. Cities, 60, 234-245.

2. Anthopoulos L., Fitsilis P. (2010), "From digital to ubiquitous cities: Defining a common architecture for urban development." Intelligent Environments (/E), 2010 Sixth lntemational Conference on. IEEE.

3. Anthopoulos, L. (2017). Smart utopia VS smart reality: Learning by experience from 10 smart city cases. Cities, 63, 128-148.

4. Between (2013), Smart City Index-Confrontarsi per diventare smart, Report 2013.

5. Caragliu A., Del Bo C., Nijkamp P. (2011), "Smart cities in Europe", Joumal of Urban Technology, 18, 2, p. 6582.

6. Cleland, B., Wallace, J., \& Black, M. (2018). The 'engage'System: Using Real-Time Digital Technologies to Support Citizen-Centred Design in Government. In User Centric E-Government (pp. 183-201). Springer,.

7. Cocchia, A. (2014). Smart and digital city: A systematic literature review. In Smart city (pp. 13-43). Springer, Cham.

8. Cutaia L., Morabito R. (2012), Sostenibilità dei sistemi produttivi: strumenti e tecnologie verso la green economy, ENEA

9. Dameri R.P. (2012), "Defining an evaluation framework for digital cities implementation." Information Society (iSociety), 2012 lntemational Conference on, IEEE, 2012.

10. Dameri R.P. (2013), "Searching for Smart City definition: a comprehensive proposal", Intemational Joumal of Computers \& Technology, 11, 5.

11. Giffinger R., Fertner C., Kramar H., Meijers E., PlichlerMilhanovic N. (2007), Smart Cities: Ranking of European medium-sized cities, Centre of Regional Science, Vienna.

12. Hammer S., Kamal-Chaoui L., Robert A., Plouin M. (2011), "Cities and Green Growth: A Conceptual Framework", Oecd Regional Development Working Papers 2011/08, Oecd Publishing, doi: $10.1787 / 5 \mathrm{~kg} 0 \mathrm{tflmzx} 34$-en.

13. Lamboglia, R., Cardoni, A., Dameri, R. P., \& Mancini, D. (Eds.). (2018). Network, Smart and Open: Three Keywords for Information Systems Innovation (Vol. 24). Springer.

14. Nam T., Pardo T. (2011), "Conceptualizing smart city with dimensions of technology, people, and institutions." Proceedings of the 12th Annua/ Intemationa/ Digital Govemment Research Conference: Digital Govemment

15. Oecd (2010a), Cities and Climate Change.

16. OECD (2010b). Good Govemance far Digital Po/icies: How to Get the Most Out of ICT: The Case of Spain's Pian Avanza, OECD, November. 
17. Oecd (2013), Green Growth in Cities, Oecd Green Growth Studies, Oecd Publishing. http://dx.doi.org/10.1787/9789264195325-en

18. Pardo T., Taewoo N. (2011), "Conceptualizing Smart City with Dimensions of Technology, People, and Institutions", Proceedings of the 12th Annua/ Intemational Conference on Digital Govemment Research, ACM New York p. 282-291.

19. Schuler D. (2002), Digital cities and digital citizens, in Tanabe M., van den Besselaar P., lshida T. (eds.), Digital
Cities Il: Computational and Sociologica/ Approaches, Springer Berlin Heidelberg, p. 71-85.

20. Siemens (2012), EfficienCITIES.Città-modello per lo sviluppo del Paese, Cittalia. Siemens-Economist Intelligence Unit (2009), European Green City lndex.

21. Zhuhadar, L., Thrasher, E., Marklin, S., \& de Pablos, P. O. (2017). The next wave of innovation-Review of smart cities intelligent operation systems. Computers in Human Behavior, 66, 273-281. 